\title{
Analysis of Mean and Volatility Spillovers Using BRIC Countries, Regional and World Equity Index Returns
}

\author{
Ramaprasad Bhar \\ The University of New South Wales \\ Biljana Nikolova \\ ANZ Banking Group Ltd
}

\begin{abstract}
This paper analyses the degree of integration of the BRIC countries on a regional and global basis, achieved by using daily equity index level data. The paper concludes that a high degree of integration exists between the BRIC countries and their respective regions, and to a lesser extent, the rest of the world. Regional trends are found to have a much greater influence than world trends upon the stock return process of the BRIC countries. The world index returns, and most likely the US equity market returns, have a significant influence upon the variance of returns seen across Brazil, Russia and India. China is the only country where there exists a negative relationship between volatility spillover effects on a regional and global basis. This suggests existence of diversification opportunities for investment managers. Global portfolio managers can still add value from investments in these countries, however the increased levels of integration of these economies highlight the need for portfolio stock selection strategies as well as investment in specific growth areas within these economies, rather than taking a position in the country index.
\end{abstract}

- JEL classification: E37, G15

- Keywords: Volatility spillover, GARCH-in-Mean, Market integration

\footnotetext{
*Corresponding address: Ramaprasad Bhar, School of Banking and Finance, The University of New South Wales, Sydney 2052, AUSTRALIA, Email: R.Bhar@unsw.edu.au

C2007-Center for International Economics, Sejong Institution, All Rights Reserved.
} 


\section{Introduction}

Markets are considered integrated when assets of identical risk, through market efficiency, command the same expected return irrespective of their domicile. Interest in the process of integration of international financial markets have triggered a considerable amount of work in the area of spillover effects.

Information transmission between markets can be measured through mean returns and volatility. Past research efforts, such as King and Wadhwani (1991), Cheung and $\mathrm{Ng}$ (1992), Theodossiou and Lee (1993) and Susmel and Engle (1994), concentrate on volatility and mean spill over effects. They have found that significant spillover effects emanate from the US market to other national stock markets and that structures of information transmission have changed since the October 1987 stock market crash.

This paper uses the mean stock return and volatility spill over effects emanating from regional and world indices, on four emerging markets, Brazil, Russia, India and China, in order to measure the level of integration of these countries within their respective regions and the world.

BRIC is the term used to refer to the combination of Brazil, Russia, India and China. The term was first prominently used in the thesis of Goldman Sachs investment bank (Wilson and Purushothaman 2003). This paper argued that the economies of the BRIC countries are rapidly developing and that by the year 2050 they will outperform most of the current richest countries of the world. This forecast is dependant upon the BRICs maintaining policies and developing institutions that are supportive of growth. Higher growth in these economies is expected to see the weighting of the BRICs in investment portfolios rise sharply.

Theory suggests that the expected returns from investments in emerging markets should reduce following greater integration of the emerging market within the world economy (Bekaert and Harvey 2002). Direct effect of increased integration leads to lower expected returns, due to rise in equity prices as foreign investors invest in emerging market assets with potential diversification benefits. This is accompanied by an increase in beta, as a result of greater sensitivity of the local market to world events, which implies higher expected returns. De Jong and De Roon (2005) considered these concepts by allowing for time variation in betas in their study of time varying market integration and expected returns of 30 emerging markets across Latin America, Asia, the Far East, Europe, the Mid-east and Africa. They concluded that an average annual decrease in local and regional segmentation 
of 0.055 , on a $[0,1]$ scale, induces a decrease in returns of about $4.5 \%$ per year for these countries. This indicates that the covariance between the emerging and world markets is much smaller than the local variance.

In addition, it should be noted that the increased level of correlation of emerging market equity returns with equity returns in the developed world in the postliberalization period results in reduction in diversification benefits.

Based on the above, in diversifying their portfolios towards emerging markets, rational international investors should consider that the integration process might lower expected returns and increase correlations between emerging market and world market returns (Bekaert and Harvey 2003). As an extension to this concept, the empirical analysis conducted by Fernandes (2003) which studies the implications of globalisation to international asset allocation, found that aggregate emerging market investment in the post-liberalization period does not provide significant diversification benefits. The author further concluded that country and stock selection strategies, for the purpose of identifying specific industry segments with potential diversification benefits, are imperative if global portfolio managers want to outperform benchmarks.

Wilson and Purushothaman (2003) in the Glodman and Sachs study proposed that the growth and higher returns of the BRIC countries should persist over the next 50 years and lead to a sharp rise of the BRICs in global investment portfolios. As an extension to this proposition, and based on the level of mean and volatility spillover effects from the world and regional indices on the BRIC countries, we find that a high degree of integration exists between the BRIC countries and their respective regions, and to a lesser extent, the rest of the world. There is no doubt that the BRIC economies will continue to grow in years to come. However, knowing the effects of market integration on equity returns and diversification benefits, the increased levels of integration displayed by the BRIC economies regionally and globally highlights the need for employment of portfolio stock selection strategies and investment in specific growth areas within these economies, as opposed to taking a position in the country index.

Market integration induces a structural change in the capital markets of an emerging country. Hence, for any empirical analysis, it is important to know the date of these structural changes. The BRICs went through the stages of liberalization in the early to mid nineties, enjoying rapid economic growth over the past decade. They are gaining increasing influence in world capital markets. If liberalization is effective it is presumed to lead to market integration, which in turn 
has an effect on both the financial and real sectors of developing countries. Bekaert, Harvey and Lundblad (2003) define the official equity liberalization of countries as "the date of formal regulatory change after which foreign investors officially have the opportunity to invest in domestic equity securities and domestic investors have the right to transact in foreign equity securities abroad." Based on this definition, Bekaert and Harvey (2000) identify the official liberalization dates for the BRIC countries as May 1991 for Brazil, January 1994 for Russia, February 1992 for India and July 1993 for China.

This paper concentrates on measuring the effect of the mean and volatility spillovers of world and regional markets on all BRIC countries during the post liberalisation period (January 1995 - December 2004). The mean and volatility spillovers in turn, are indicators of the level of integration demonstrated by these countries on a regional and global basis.

The remainder of the paper is organised as follows: section two defines the methodology used to measure the level of spillover effects; section three provides information on the data used in the paper, section four contains the empirical results and discussion of same and section five is the conclusion.

\section{Methodology}

The two-stage GARCH-in-mean approach (GARCH-M), as specified by Liu and Pan (1997) has been used to examine the influence of global and regional equity index returns and volatility on the BRIC economies.

In the first stage, the relevant regional and global equity index return series are modelled through an ARMA $(1,1)-G A R C H(1,1)-M$ model as follows:

$$
\begin{gathered}
r_{k, t}=\varphi_{0}+\varphi_{1} r_{k, t-1}+\varphi_{2} v_{k, t}+\varphi_{3} \varepsilon_{k, t-1}+\varepsilon_{k, t}, \varepsilon_{k, t} \sim N\left(0, v_{k, t}\right) \\
v_{k, t}=\alpha_{0}+\alpha_{1} v_{k, t-1}+\alpha_{2} \varepsilon_{k, t-1}^{2}
\end{gathered}
$$

where $r_{k, t}$ is the weekly return of equity index $k$ (world index or regional index) at time $t$, and $\varepsilon_{k, t}$ is the residual (or unexpected return) which is normally distributed with mean zero and time-conditional variance $v_{k, t}$. The inclusion of $\operatorname{ARMA}(1,1)$ and/or MA (1) structure in the model is designed to adjust for possible serial correlation in the data.

In the second stage, mean return and volatility spillover effects across markets are estimated by obtaining the standardised residual and its square in the first stage 
and substituting them into the mean and volatility equations of other markets as follows:

$$
\begin{gathered}
r_{j, t}=\varphi_{0}+\varphi_{j, 1} r_{j, t-1}+\varphi_{j, 2} v_{j, t}+\varphi_{j, 3} \varepsilon_{j, t-1}+\lambda_{J} \varepsilon_{k, t}+\varepsilon_{j, t}, \quad \varepsilon_{j, t} \sim N\left(0, v_{j, t}\right) \\
v_{j, t}=\alpha_{j, 0}+\alpha_{j, 1} v_{j, t-1}+\alpha_{j, 2} \varepsilon_{j, t-1}^{2}+\gamma_{j} e_{k, t}^{2}
\end{gathered}
$$

where $e_{k, t}$ is the standardised residual series for the world index or the relevant regional index, and is capturing the mean return spillover effect from these sources. In order to examine the volatility spillover, the exogenous variable $e_{k, t}^{2}$ - the square of the standardised residual series is included in the conditional volatility equation and is defined as $e_{k, t}=\varepsilon_{k, t} \sqrt{v_{k, t}}$. The subscript $\mathrm{j}$ in each of the equations (3) and (4) refers to one of the BRIC countries.

Each of the BRIC stock exchanges is located in a different time zone. As such, they operate different trading hours. Given that almost fifty percent of the world index market capitalisation is represented by US stocks, the New York stock exchange trading hours have been used as a proxy to determine the timing differences in trading hours between the world and the BRIC indices. The time difference between Brazil and NY is one hour only, whilst the time difference between Russia, India and China compared with NY are eight hours, eleven hours and twelve hours respectively. This means that a shock in the World market during day $t$ will not be reflected in the Russian, Indian and Chinese stock exchanges until day $t+1$. Therefore, the appropriate paring time to be used in the model above is $t$ $l$ for the world and $t$ for Russia, India and China.

\section{Data}

The data samples, forming the basis for analysis of this paper, are the daily closing stock market indices for Brazil (Bovespa), Russia (AKMI Composite), India (Sensex), China (Shanghai Composite), Morgan Stanley's All Countries World Index, Financial Times All Countries Europe Index, Financial Times All Countries Asia-Pacific Index and Financial Times All Countries Americas Index, for the period between January 1995 and December 2004. Daily closing equity market index prices were used for working days only, that is, weekends were excluded from the data sample. For missing values due to holidays in one market, while the other markets are open, the previous day's closing price was used. The data were sourced from Bloomberg. 
Daily equity index returns were computed as the natural logarithm of the price index relative. Tests for serial correlation in the absolute value of daily returns as well as the squared value of daily returns confirmed that the existence of conditional heteroskedasticity in the daily equity index returns is highly likely. This justifies the use of models from the ARCH family.

$\operatorname{ARMA}(1,1)-G A R C H(1,1)-i n$ Mean and/or MA(1) processes were modelled for the BRIC equity index returns, the world equity index return and the regional equity index returns for the post-liberalization period. Portmanteau (Q) test statistic for serial correlation in both standardised raw and squared residuals confirm that the specified ARMA (1,1)-GARCH (1,1)-in Mean and/or MA(1) models, specified as equations (1) and (2), in general fit the data well, that is, the model has taken care of the fat-tails and time-varying volatility in the data.

Skewness and kurtosis tests for both standardized residuals and squared standardized residuals are zero for all BRIC countries and the world. Shapiro-Wilk $\mathrm{W}$ test for normal data confirms normality for both standard residuals and square of standard residuals for all BRIC countries, the world and the three regions.

\section{Results and Discussions}

The mean and volatility spillover effects from the world equity index and reflected across each respective BRIC equity index over the post liberalization period are reported in Table 1. All ARCH and GARCH coefficients are statistically significant at the five percent level for all BRIC countries as well as the world equity index returns. The significant $t$ statistics of ë and ã suggest that the conditional mean returns and the volatility of the BRIC countries are influenced by the world equity index returns.

The mean spillover effects from the world equity index returns are positive for all BRIC countries, whilst the volatility spill over effects are positive for Brazil, Russia and India but negative and significant for China at -0.4983 . This implies negative correlation between the world equity index returns and the Chinese equity index returns, which in turn suggest existence of portfolio diversification opportunities for international portfolio managers.

Also, whilst the $t$ statistics for the volatility spillover variables for Brazil and India are statistically significant, the magnitude of the coefficients is relatively small for both countries ( 0.0077 for Brazil and 0.0071 for India). This suggests that the level of influence of the world equity index returns on the overall variance of 
Table 1. Mean and volatility spillovers from world index estimated from an ARMA $(1,1)-$ GARCH $(1,1)$-in-mean model

\begin{tabular}{cccccc}
\hline & World & Brazil & Russia & India & China \\
\hline$\varphi_{0}$ & -0.0068 & 0.0556 & 0.1446 & 0.0968 & -0.0576 \\
& $(0.0313)$ & $(0.0609)$ & $(0.0813)$ & $(0.0630)$ & $(0.0340)$ \\
$\varphi_{1}$ & & & 0.5048 & 0.1364 & 0.5555 \\
& & & $(0.0489)$ & $(0.1387)$ & $(0.1793)$ \\
$\varphi_{2}$ & 0.0589 & 0.0237 & 0.0184 & -0.0068 & 0.0220 \\
& $(0.0458)$ & $(0.0117)$ & $(0.0173)$ & $(0.0268)$ & $(0.0140)$ \\
$\varphi_{3}$ & 0.1958 & 0.0945 & -0.1347 & 0.0180 & -0.4822 \\
& $(0.0214)$ & $(0.0226)$ & $(0.0567)$ & $(0.1415)$ & $(0.1955)$ \\
$\lambda$ & & 0.3037 & 0.0805 & 0.0422 & 0.0165 \\
& & $(0.0126)$ & $(0.0105)$ & $(0.0104)$ & $(0.0083)$ \\
$\alpha_{0}$ & 0.0083 & -1.5450 & -1.1243 & -2.0286 & -1.2621 \\
& $(0.0013)$ & $(0.1574)$ & $(0.0741)$ & $(0.1466)$ & $(0.1312)$ \\
$\alpha_{1}$ & 0.0613 & 0.1538 & 0.1806 & 0.1238 & 0.2511 \\
& $(0.0049)$ & $(0.0123)$ & $(0.0143)$ & $(0.0108)$ & $(0.0155)$ \\
$\alpha_{2}$ & 0.9302 & 0.8068 & 0.7587 & 0.8270 & 0.7643 \\
& $(0.0051)$ & $(0.0145)$ & $(0.0131)$ & $(0.0129)$ & $(0.0103)$ \\
$\gamma$ & & 0.0077 & 0.0125 & 0.0071 & -0.4983 \\
& & $(0.0021)$ & $(0.0003)$ & $(0.0014)$ & $(0.1299)$ \\
$\mathrm{Q}(24)$ & 0.542 & Residual Diagnostics & & \\
$\mathrm{Q}(24) \mathrm{Sq}$ & 0.987 & 0.149 & 0.331 & 0.014 & 0.052 \\
$\mathrm{D}$ & 0.197 & 1.000 & 0.791 & 0.994 \\
\hline
\end{tabular}

Data used are daily stock index returns for the period January 1995 to December 2004. The numbers in parentheses below the parameter estimates are standard errors. The entries for residual diagnostics series are p-values. Q (24) refers to the Portmanteau statistic with the null hypothesis of no residual serial correlations measured with a lag of 24. Similarly, Q (24) Sq refers to the same test with squared residual series with a null hypothesis of no residual $\mathrm{ARCH}$ effect. Large p-value entries here would indicate that there are no serial correlations or ARCH effect in the model residuals.

the national equity index returns of these countries is nominal.

Table 2 contains the results for the mean and volatility spillover effects from the Americas regional equity index on Brazilian equity index for the same period. Both the mean and volatility spillover effects coefficients are positive and statistically significant. There is evidence of a greater regional influence on both the mean and variance level than that attributed to the world equity index. The regional mean spillover effects coefficient is at 0.4510 compared to the world mean spillover effects coefficient of 0.3037 , while the variance spillover effects coefficient is 0.0206 compared to the world variance spillover effects coefficient of 0.0077.

The mean and volatility spillover effects from the European regional equity 
Table 2. Mean and volatility spillovers from regional index estimated from an ARMA (1, 1)-GARCH $(1,1)$-in-mean model

\begin{tabular}{ccc}
\hline & Americas & Brazil \\
\hline$\varphi_{0}$ & -0.1398 & 0.0550 \\
& $(0.0667)$ & $(0.0645)$ \\
$\varphi_{1}$ & -0.8093 & \\
& $(0.3400)$ & \\
$\varphi_{2}$ & 0.0795 & 0.0226 \\
& $(0.0388)$ & $0.0117)$ \\
$\varphi_{3}$ & 0.7963 & 0.0226 \\
& $(0.3516)$ & $(0.1011)$ \\
$\lambda$ & & 0.4510 \\
& & $(0.0213)$ \\
$\alpha_{0}$ & 0.1974 & -1.3336 \\
& $(0.0213)$ & $(0.1418)$ \\
$\alpha_{1}$ & 0.1036 & 0.1557 \\
& $(0.0074)$ & $(0.0122)$ \\
$\alpha_{2}$ & 0.7883 & 0.7971 \\
& $(0.0169)$ & $(0.0157)$ \\
$\gamma$ & & 0.0206 \\
& Residual Diagnostics & $(0.0076)$ \\
$\mathrm{Q}(24)$ & 0.159 & 0.123 \\
$\mathrm{Q}(24) \mathrm{Sq}$ & 0.959 & 0.801 \\
\hline
\end{tabular}

Data used are daily stock index returns for the period January 1995 to December 2004. The numbers in parentheses below the parameter estimates are standard errors. The entries for residual diagnostics series are p-values. Q (24) refers to the Portmanteau statistic with the null hypothesis of no residual serial correlations measured with a lag of 24. Similarly, Q (24) Sq refers to the same test with squared residual series with a null hypothesis of no residual ARCH effect. Large p-value entries here would indicate that there are no serial correlations or ARCH effect in the model residuals.

index on the Russian equity index are reported in Table 3. The level of mean spillover effects from the region on Russia at 0.1703 are higher than the world mean spillover effects of 0.0805 , however it is interesting to note that the level of volatility spillover effects from the region at 0.0053 are lower than the spillover effects from the world of 0.0125 . This suggests that economies in close proximity to Russia have a large influence in the equity price creation process for Russian stocks. However, the level of variance in returns is influenced by broader international trends.

Table 4 reports the mean and volatility spillover effects results from the AsiaPacific region on both India and China. Similar to Russia, the mean spillover 
Table 3. Mean and volatility spillovers from regional index estimated from an ARMA (1, 1)-GARCH $(1,1)$-in-mean model

\begin{tabular}{|c|c|c|}
\hline & Europe & Russia \\
\hline$\varphi_{0}$ & $\begin{array}{c}0.0084 \\
(0.0465)\end{array}$ & $\begin{array}{c}0.1608 \\
(0.0821)\end{array}$ \\
\hline$\varphi_{1}$ & $\begin{array}{c}0.9658 \\
(0.0237)\end{array}$ & $\begin{array}{c}0.4976 \\
(0.0494)\end{array}$ \\
\hline$\varphi_{2}$ & $\begin{array}{c}0.0323 \\
(0.0244)\end{array}$ & $\begin{array}{c}0.0130 \\
(0.0179)\end{array}$ \\
\hline$\varphi_{3}$ & $\begin{array}{l}-0.9429 \\
(0.0302)\end{array}$ & $\begin{array}{l}-0.1143 \\
(0.0580)\end{array}$ \\
\hline$\lambda$ & & $\begin{array}{c}0.1703 \\
(0.0158)\end{array}$ \\
\hline$\alpha_{0}$ & $\begin{array}{c}0.2456 \\
(0.0153)\end{array}$ & $\begin{array}{c}-1.7124 \\
(0.0577)\end{array}$ \\
\hline$\alpha_{1}$ & $\begin{array}{c}0.3560 \\
(0.0191)\end{array}$ & $\begin{array}{c}0.1571 \\
(0.0104)\end{array}$ \\
\hline$\alpha_{2}$ & $\begin{array}{c}0.5706 \\
(0.0180)\end{array}$ & $\begin{array}{c}0.8219 \\
(0.0057)\end{array}$ \\
\hline$\gamma$ & & $\begin{array}{c}0.0053 \\
(0.0011)\end{array}$ \\
\hline & Residual Diagnostics & \\
\hline $\mathrm{Q}(24)$ & 0.244 & 0.513 \\
\hline $\mathrm{Q}(24) \mathrm{Sq}$ & 1.000 & 1.000 \\
\hline
\end{tabular}

Data used are daily stock index returns for the period January 1995 to December 2004. The numbers in parentheses below the parameter estimates are standard errors. The entries for residual diagnostics series are p-values. Q (24) refers to the Portmanteau statistic with the null hypothesis of no residual serial correlations measured with a lag of 24. Similarly, Q (24) Sq refers to the same test with squared residual series with a null hypothesis of no residual ARCH effect. Large p-value entries here would indicate that there are no serial correlations or ARCH effect in the model residuals.

effects coefficient for India at 0.1173 is higher that the mean spillover effects coefficient from the world of 0.0422 , while the volatility spillover coefficient from the region of 0.0039 is lower than the world variance spillover effects coefficient of 0.0071 . This suggests a higher degree of regional influence in the process of equity price creation, however higher broader international influence over the variance of returns of stocks in India.

Going back to the comment that the US stock market represents almost fifty percent of the world stock index capitalisation, the results as explained above could imply that the US stock market has greater influence over the level of variance in the returns of Russian and Indian equities as opposed to the respective European 
Table 4. Mean and volatility spillovers from regional index estimated from an ARMA (1, 1)-GARCH $(1,1)$-in-Mean Model

\begin{tabular}{|c|c|c|c|}
\hline & Asia-Pacific & China & India \\
\hline$\varphi_{0}$ & $\begin{array}{l}-0.0881 \\
(0.0652)\end{array}$ & $\begin{array}{l}-0.0352 \\
(0.0382)\end{array}$ & $\begin{array}{c}0.0755 \\
(0.0612)\end{array}$ \\
\hline$\varphi_{1}$ & $\begin{array}{l}-0.1768 \\
(0.9964)\end{array}$ & $\begin{array}{c}0.6263 \\
(0.1752)\end{array}$ & $\begin{array}{c}0.1595 \\
(0.1337)\end{array}$ \\
\hline$\varphi_{2}$ & $\begin{array}{c}0.0244 \\
(0.0243)\end{array}$ & $\begin{array}{c}0.0210 \\
(0.0157)\end{array}$ & $\begin{array}{c}0.0022 \\
(0.0263)\end{array}$ \\
\hline$\varphi_{3}$ & $\begin{array}{c}0.2005 \\
(0.9902)\end{array}$ & $\begin{array}{l}-0.5671 \\
(0.1903)\end{array}$ & $\begin{array}{c}0.0001 \\
(0.1366)\end{array}$ \\
\hline$\lambda$ & & $\begin{array}{c}0.0314 \\
(0.0175)\end{array}$ & $\begin{array}{c}0.1173 \\
(0.0196)\end{array}$ \\
\hline$\alpha_{0}$ & $\begin{array}{c}0.0971 \\
(0.0155)\end{array}$ & $\begin{array}{l}-0.5054 \\
(0.0850)\end{array}$ & $\begin{array}{l}-1.9210 \\
(0.1517)\end{array}$ \\
\hline$\alpha_{1}$ & $\begin{array}{c}0.0733 \\
(0.0052)\end{array}$ & $\begin{array}{c}0.1545 \\
(0.0103)\end{array}$ & $\begin{array}{c}0.1448 \\
(0.0132)\end{array}$ \\
\hline$\alpha_{2}$ & $\begin{array}{c}0.8974 \\
(0.0094)\end{array}$ & $\begin{array}{c}0.8318 \\
(0.0088)\end{array}$ & $\begin{array}{c}0.8064 \\
(0.0154)\end{array}$ \\
\hline$\gamma$ & & $\begin{array}{l}-13.385 \\
(2.3287)\end{array}$ & $\begin{array}{c}0.0039 \\
(0.0015)\end{array}$ \\
\hline \multicolumn{4}{|c|}{ Residual Diagnostics } \\
\hline $\mathrm{Q}(24)$ & 0.145 & 0.086 & 0.011 \\
\hline $\mathrm{Q}(24) \mathrm{Sq}$ & 1.000 & 0.991 & 0.711 \\
\hline
\end{tabular}

Data used are daily stock index returns for the period January 1995 to December 2004. The numbers in parentheses below the parameter estimates are standard errors. The entries for residual diagnostics series are p-values. Q (24) refers to the Portmanteau statistic with the null hypothesis of no residual serial correlations measured with a lag of 24. Similarly, Q (24) Sq refers to the same test with squared residual series with a null hypothesis of no residual ARCH effect. Large p-value entries here would indicate that there are no serial correlations or ARCH effect in the model residuals.

and Asia-Pacific regional markets. Also, in relation to the results for Brazil, it is evident that there is a higher level of regional influence regarding the variance in returns, which could be due to the US stocks representing a higher proportion of the Americas equity returns index in comparison to the world equity returns index.

The mean spillover effects coefficient for China from the region of 0.0314 is also higher than the world mean spillover effects coefficient of 0.0165 . However, unlike the results for the other countries covered in this study, the volatility spillover effects coefficient is large and negative on both a regional and global basis at -13.385 and -0.4983 respectively. The regional equity index influence is higher than the world equity index influence in terms of both mean and volatility 
spillover effects, which indicates higher level of regional rather than international integration of the Chinese economy. As mentioned earlier, the negative sign in front of the volatility spillover effects coefficient indicates existence of diversification opportunities for both regional and international investors and portfolio managers.

It is evident form the results that all BRIC countries have begun the process of integration both regionally and to a somewhat lesser extent internationally. However, the moderate magnitude of spillover coefficients suggests that this process is ongoing. This implies that international investors and portfolio managers can still add significant value through investments in these economies due to existence of diversification opportunities. It should be noted however, that due to the increasing levels of integration, investors should start to consider investments in specific growth areas within these countries, particularly in the cases of Brazil, Russia and India, as the level of diversification opportunities on a country level basis will reduce as the level of integration progresses furthers.

\section{Conclusions}

The purpose of this paper is to measure the level of integration of the BRIC economies on a regional and global basis since their liberalisation. The mean and volatility spillover effects for all BRIC countries from the world and respective regional equity index returns over the period January 1995 to December 2004, are used as a proxy for the level of integration of the BRIC economies regionally and globally.

The two-stage GARCH-in-mean approach (GARCH-M), as specified by Liu and Pan (1997) is used to examine the international transmission of equity index returns and volatility to the BRIC economies.

The results of this study suggest that the conditional mean returns and the volatility of the BRIC countries are influenced by the world. The mean spillover effects from the world are positive for all BRIC countries, whilst the volatility spill over effects are positive for Brazil, Russia and India but negative and significant for China. This implies negative correlation between the world equity index returns and the Chinese equity index returns, and suggests existence of portfolio diversification opportunities for international investors and portfolio managers.

Further, it is evident that regional markets have greater influence upon the equity price creation process in all BRIC countries as opposed to the world, given that the 
coefficients for all BRIC countries are statistically significant and positive.

The results for the volatility spillover effects were somewhat more versatile. Regional rather than global influences have a greater effect on return volatility in Brazil. This is most likely due to the US market representing a higher proportion of the Americas regional equities returns index than the world equities returns index. Volatility spillover effects for both Russia and India were greater on a global, as opposed to regional basis. China is the only country for which the volatility of returns is negatively related to both world and regional equity index returns, and regional influence is greater than any broader international influence.

Based on the results, it is deducted that regional trends have greater influence than the world in the equity price creation process for all BRIC countries. This indicates the presence of regional integration of all BRIC countries in terms of equity price creation. In relation to the volatility of returns, it is implied that the world, and most likely the US equity market, significantly influences the variance of returns for Brazil, Russia and India (mean and variance spillover effects study from the US stock index to the BRIC countries could be conducted as an extension to this paper). China is the only country for which there is a negative relationship for the volatility spillover effects for both the world and regionally. This suggests existence of diversification opportunities for international investors and portfolio managers.

All BRIC countries have begun the process of integration on a regional, and to a lesser extent, global basis. However the moderate magnitude of spillover coefficients suggests that this process is ongoing. This implies that international investors and portfolio managers can still add significant value through investments in these economies due to existence of diversification opportunities. It should however be noted that the increased levels of integration of these economies regionally and across the rest of the world highlights the need for employment of portfolio stock selection strategies and investment in specific growth areas within these economies, rather than taking a position in the country index. Further areas of interest for investors, and an extension to this paper, could be identification of specific growth areas and investment opportunities in the BRIC countries.

Received 12 September 2006, Accepted 15 January 2007 


\section{References}

Bekaert, G. (1995), Market integration and investment barriers in emerging equity markets, World Bank Economic Review, 9, 75-107.

Bekaert G. and Harvey R. H. (2000), Foreign speculators and emerging equity markets, Journal of Finance, 55, 565-614.

Bekaert, G., Harvey, C.R., and Lumsdaine, R. (2002), Dating the integration of world capital markets, Journal of Financial Economics, 65(2), 203-248.

Bekaert, G and Harvey R.H. (2003), Emerging Markets Finance, Journal of Empirical Finance, 10, 3-55.

Bollerslev, T. (1986), Generalized Autoregressive Conditional Heteroskedasticity, Journal of Econometrics, 31, 307-327.

Bollerslev, T., Chou, R. Y., and Kroner, K. (1992), ARCH modelling in finance: A selective review of theory and empirical evidence, Journal of Econometrics, 52, 559.

Cheung, Y. W. and Ng, L. K. (1992), Interactions between the US and Japan stock market indices, Journal of International Financial Markets, Institutions and Money, 2, 5170.

De Jong, F. and De Roon, F. A. (2005), Time varying market integration and expected returns in emerging markets, Journal of Financial Economics, 78, 583-613

Fernandes, N. (2003), What level of portfolio disaggregation in emerging markets investments?, WP SSRN.

Greene, W. H. (2005), Econometric Analysis, Pearson Education Inc., Upper Saddle River, New Jersey.

Griffin, J.M., Nardari, F., and Stulz, R.M., (2002), Daily cross-border equity flows: Pushed or pulled?, Working Paper, The Ohio State University.

King, M. and Wadhwani, S. (1991), Transmission of volatility between stock markets, Review of Financial Studies, 3, 5-33.

Liu, Y. A. and Pan, M. S. (1997), Mean and volatility spillover effects in the US and Pacific-Basin stock markets, Multinational Finance Journal, 1(1), 47-62.

MacKinnon, J. G., (1999), Economics 872: lecture notes, Queen's University, spring 1999.

Stulz, R.M. (1999), International portfolio flows and security markets, Feldstein, M. (Ed.), International Capital Flows, National Bureau of Economic Research and University of Chicago Press, 257-293.

Susmel, R. and Engle, R. F. (1994), Hourly volatility spillovers between international equity markets, Journal of International Money and Finance, 13, 3-25.

Theodossiou P and Lee U, (1993), Mean and volatility spillovers across major national stock markets: further empirical evidence, Journal of Financial Research, 16, 33750.

Wilson, D. and Purushothaman, R. (2003), Dreaming with BRICs: The path to 2050, Goldman. 